\title{
Spontaneous Internal Anal Sphincter Relaxation During High-resolution Anorectal Manometry Is Associated With Peripheral Neuropathy and Higher Charlson Comorbidity Scores in Patients With Defecatory Disorders
}

\begin{abstract}
Tae Hee Lee, ${ }^{1 *}$ Joon Seong Lee, ${ }^{1}$ Jeeyeon Kim, ${ }^{1}$ Jin-Oh Kim, ${ }^{1}$ Hyun Gun Kim, ${ }^{1}$ Seong Ran Jeon, ${ }^{1}$ Su Jin Hong, ${ }^{2}$ Young Sin Cho, ${ }^{3}$ and Suyeon Park ${ }^{4}$
${ }^{1}$ Institute for Digestive Research, Digestive Disease Center Soonchunhyang University College of Medicine, Seoul, Korea; ${ }^{2}$ Department of Internal Medicine, Soonchunhyang University College of Medicine, Bucheon, Gyeonggi-do, Korea; ${ }^{3}$ Division of Gastroenterology, Cheonan Hospital, Soonchunhyang University College of Medicine, Cheonan, Chungcheongnam-do, Korea; and ${ }^{4}$ Department of biostatistics, Soonchunhyang University Seoul Hospital, Seoul, Korea
\end{abstract}

\section{Background/Aims}

We aimed to evaluate associations between comorbidities, peripheral neuropathy, and spontaneous internal anal sphincter relaxation (SAR) in patients with defecatory disorders.

\section{Methods}

A patient was considered to exhibit SAR during high-resolution anorectal manometry (HR-ARM) when the nadir pressure is $<15$ $\mathrm{mmHg}$ and the time from onset to relaxation was $\geq 15$ seconds in the resting pressure frame. A case-control study was performed using HR-ARM data collected from 880 patients from January 2010 to May 2015. We identified 23 cases with SAR (median age 75 years; 15 females; 12 fecal incontinence and 11 constipation). We compared HR-ARM values, Charlson index comorbidity scores, neuropathy, and the prevalence of diseases that potentially cause neuropathy between controls and SAR patients. Each SAR case was compared to 3 controls. Controls were selected to match the age, gender, and examination year of each SAR case.

\section{Results}

Compared to controls (26.1\%), SAR patients (52.2\%) exhibited a significantly higher frequency of fecal incontinence. SAR patients also had higher Charlson index scores (5 vs $4, P=0.028$ ). Nine of 23 SAR patients $(39.1 \%)$ exhibited peripheral neuropathy - this frequency was higher than that for the control group $(11.6 \% ; P=0.003)$. Diseases that potentially cause neuropathy were observed in 17 of 23 SAR cases and 32 of 69 controls $(P=0.022)$.

\section{Conclusions}

SAR develops in patients with constipation and fecal incontinence but is more common in patients with fecal incontinence. Our controlled observational study implies that SAR is associated with peripheral neuropathy and more severe comorbidities.

(J Neurogastroenterol Motil 2020;26:362-369)

Key Words

Anal canal; Constipation; Fecal incontinence; Manometry; Relaxation

Received: June 24, 2019 Revised: November 12, 2019 Accepted: December 30, 2019

(-) This is an Open Access article distributed under the terms of the Creative Commons Attribution Non-Commercial License (http://creativecommons. org/licenses/by-nc/4.0) which permits unrestricted non-commercial use, distribution, and reproduction in any medium, provided the original work is properly cited.

*Correspondence: Tae Hee Lee, MD, PhD Institute for Digestive Research, Digestive Disease Center, Soonchunhyang University College of Medicine, 59, Daesagwan-ro, Yongsan-gu, Seoul 04401, Korea

Tel: +82-2-710-3084, Fax: +82-2-709-9696, E-mail: iman0825@schmc.ac.kr

Tae Hee Lee and Joon Seong Lee contributed equally to this work. 


\section{Introduction}

The internal anal sphincter (IAS) contributes approximately $70 \%$ of the resting anal pressure and plays a crucial role in maintaining continence. ${ }^{1}$ This pressure represents the tonic activity of the IAS. On the other hand, IAS relaxation is needed to trigger the rectoanal inhibitory reflex (RAIR) and defecation reflex. ${ }^{2}$ The IAS dysmotility spectrum includes IAS degeneration, scleroderma, radiation toxicity, diabetes mellitus, anal fissures, and internal sphincter achalasia. ${ }^{3}$ The clinical phenotype of IAS dysmotility diseases may feature chronic constipation or fecal incontinence. Previously, the IAS tone was attributed to the contractile mechanism of smooth muscle cells (ie, myogenic activity). ${ }^{2}$ However, growing evidence indicates that the interstitial cells of Cajal (ICCs), which generate slow waves and are present in the IAS, participate in tone generation. ${ }^{4,5}$ Recent studies found that the IAS tone is associated with the sum of phasic events. ${ }^{4,5}$

Anorectal manometry (ARM) is a well-established tool that is used to explore the pathophysiology of patients with chronic constipation and fecal incontinence. ${ }^{6,7}$ Recently, high-resolution ARM (HR-ARM), which incorporates a large number of closely-spaced pressure sensors, is increasingly used in clinical practice, as its spatiotemporal resolution is better than that of conventional ARM. ${ }^{1}$ Spontaneous and transient IAS relaxation episodes have been reported to develop during ARM evaluation of resting anal pressure $^{8}$; such events were termed "spontaneous internal anal sphincter relaxation (SAR)," which indicates unstable IAS tonic contraction, likely plays a major role in the development of fecal incontinence. ${ }^{9-11}$ Although 20 years have passed since SAR was first described, no other study (to our knowledge) has specifically investigated SAR in constipated patients. A subset of incontinent and constipated patients may share similar IAS characteristics, such as a patulous anus (ie, a low resting anal tone). This condition is associated with severe anal injury but may also be caused by anal denervation. ${ }^{12}$ The cause of SAR is unclear, and its clinical implications are poorly understood. It is possible that SAR may reflect an imbalance between the inhibitory IAS innervation by neuronal nitric oxide and the excitatory innervation by neuronal acetylcholine, causing an incomplete summation of the phasic waves. Therefore, the association between SAR and peripheral neuropathy should be investigated. Peripheral neuropathy causes considerable morbidity and mortality in diabetic patients. ${ }^{13}$ Additionally, fecal incontinence and chronic constipation may increase mortality risks in older patients, although more research needs to be done on this topic. ${ }^{14,15}$ The Charlson co- morbidity index (CCI) score is an indicator of mortality in patients with chronic diseases. ${ }^{16}$ Therefore, in this study, we evaluated associations among peripheral neuropathy, CCI scores, and SAR status in patients with defecatory disorders.

\section{Materials and Methods}

\section{Study Subjects}

Between August 2010 and May 2015, 880 patients with defecatory disorders were referred for HR-ARM at our motility clinic at Soonchunhyang University Seoul Hospital, Korea (Fig. 1). A defecatory disorder was defined as a structural or functional abnormality of the anorectum or pelvic floor associated with defecatory symptoms such as difficult defecation, fecal incontinence, and/or anorectal pain. Of these, 279 patients were excluded from our study because they had undergone repeated examinations, had an incomplete clinical assessment, or had incomplete HRARM assessments - ie, the time allowed for adjustment prior to recording resting anal pressure was inadequate $(<5$ minutes). We identified 23 cases exhibiting SAR. We compared each SAR case to 3 controls. Controls were selected to match the age, gender, and examination year of each SAR case. Controls meeting these criteria were selected at random with the aid of $\mathrm{R}$ version 3.6.1 software (the MatchIt package). This study was approved by the Institutional Review Board of Soonchunhyang University Seoul Hospital (SCHIRB-2019-05-001).

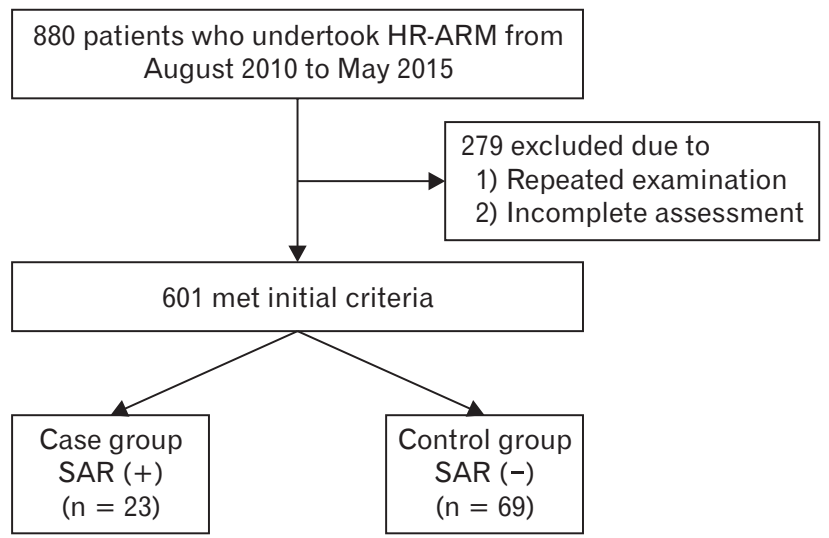

Figure 1. Flow chart of study procedure. Patients were separated into 2 groups: (1) those exhibiting spontaneous internal anal sphincter relaxation (SAR) and (2) the control group. Data from each SAR patient were compared with 3 control patients. Control patients were selected to match each SAR patient in terms of age, sex, and examination year. HR-ARM, high-resolution anorectal manometry. 


\section{High-resolution Anorectal Manometry Procedure}

HR-ARM was performed using a solid-state manometric assembly featuring 12 circumferential sensors (outer diameter: 4.2 $\mathrm{mm}$ ) spaced at 1-cm intervals (Sierra Scientific Instruments Inc, Los Angeles, CA, USA) over 12 radially dispersed sectors. The device uses proprietary pressure transduction technology (TactArray, Sierra Scientific Instruments Inc); each pressure-sensing element detects the pressure over a distance of $2.5 \mathrm{~mm}$ in each sector. The catheter was placed in the rectum and the resting anal pressure measured after an adjustment period of at least 5 minutes. To evaluate the squeezing anal pressure, pelvic floor dyssynergia, rectal sensation, and rectoanal inhibitory reflex, the following maneuvers were performed: (1) 3 squeezing maneuvers for a maximum duration of 20-30 seconds, (2) 3 bearing-down maneuvers (simulated defecations) typically for 20-30 seconds, and (3) graded balloon inflation in $10-\mathrm{mL}$ increments from $0 \mathrm{~mL}$ to $100 \mathrm{~mL}$, and thereafter in 20 $\mathrm{mL}$ increments to a maximum of $300 \mathrm{~mL}$. The threshold volumes for the first sustained sensation, urge, and maximum discomfort were recorded. We considered the patient to exhibit SAR when the nadir pressure was $<15 \mathrm{mmHg}$ and the time from onset to relaxation was $\geq 15$ seconds in the resting pressure frame during HR-ARM (Fig. 2). The extent of SAR agreement was assessed with the aid of the kappa test (which evaluates whether the extent of agreement is greater than what would be expected by chance). Kappa values of 0.40 to $0.59,0.60$ and 0.74 , and $\geq 0.75$ are considered reasonable, good, and excellent, respectively. In terms of SAR diagnosis, the extent of agreement between the 2 gastroenterologists (T.H.L. and J.S.L.) was excellent (kappa $=0.85$ ).

\section{Balloon Expulsion Test}

With patients lying in the left lateral position, a balloon containing $50 \mathrm{~mL}$ of water was inserted into the rectum. Thereafter, patients were given up to 3 minutes to evacuate the balloon (in private) while sitting. Normal expulsion was defined as the ability to expel the balloon within 1 minute.

\section{Barium Defecography}

All patients were asked to urinate before the study. No colonic preparation was required. A paste containing $250 \mathrm{~mL}$ diluted barium and $300 \mathrm{~g}$ potato starch was injected into the rectum by a mechanical applicator resembling a caulking gun until the patient reported a sustained desire to defecate. The patient was then seated on a special commode with a radiolucent plastic seat to increase the soft tissue density below the pelvis and buttocks. Examinations were performed in the sitting position and lateral images were obtained via digital fluoroscopy (Multipurpose Imaging System VesiFlex VISTA; Hitachi Medical Corporation, Medical System Operation Group, Kashiwa, Japan). The study ended when the rectum was empty or when the patient was not able to evacuate the rectal contrast after at least 60 seconds of successive attempts to defecate. Anorectal motion, rectal evacuation, and structural abnormalities (eg, rectocele and rectal intussusception) were evaluated by an experienced gastroenterologist (T.H.L.) blinded to the results of other tests, at rest, during squeezing, at 30 seconds and 60 seconds after defecation, and after patients went to the toilet. Based on data from previous studies using healthy volunteers, evacuation of $>66 \%$ of the rectal contrast within either 30 seconds $^{17}$ or 60 seconds $^{18}$ was de-

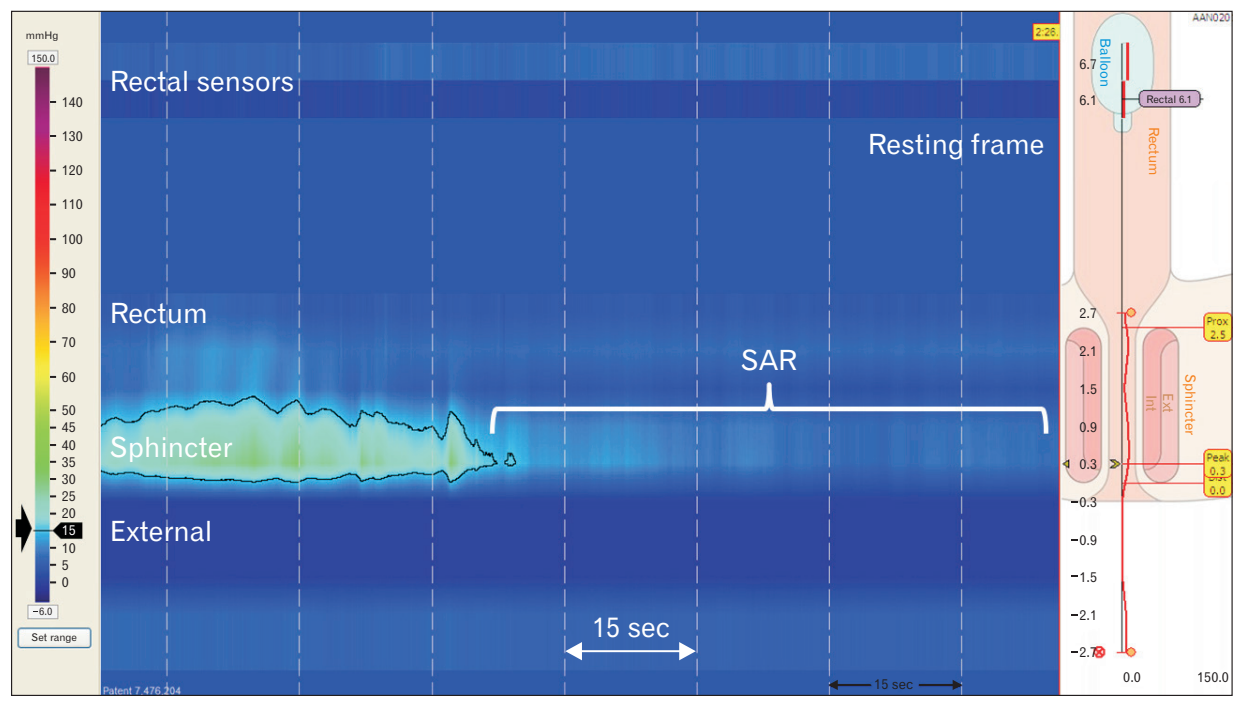

Figure 2. A patient was considered to exhibit spontaneous internal anal sphincter relaxation (SAR) during high-resolution anorectal manometry (HR-ARM) when the nadir pressure was $<15 \mathrm{mmHg}$ and the duration from onset to relaxation was $\geq 15$ seconds in the resting pressure frame. 
fined as normal. Rectal prolapse was classified as recto-rectal, rectoanal, or external. ${ }^{19}$ The location of the anorectal junction (ARJ) was measured relative to the upper surface of the commode at rest, and during squeezing and evacuation. When the ARJ was above the upper surface of the commode, the value was considered negative, and vice versa.

\section{Collected Data}

We recorded the age, sex, body mass index, and clinical information of each patient. Patients were considered to exhibit chronic constipation if they met 2 of the following criteria over the last 6 months: (1) fewer than 3 bowel movements per week, (2) straining during at least $25 \%$ of defecations, (3) lumpy or hard stools during at least $25 \%$ of defecations, (4) a sensation of incomplete evacuation after at least $25 \%$ of defecations, (5) a sensation of anorectal obstruction during at least $25 \%$ of defecations, and (6) the use of manual maneuvers to facilitate at least $25 \%$ of defecations. Patients with a Wexner score $\geq 5$ were considered to exhibit fecal incontinence. ${ }^{20}$ When patients exhibited both fecal incontinence and constipation, we considered these patients as fecally incontinent only.

The CCI was developed to measure mortality risks associated with comorbid diseases. ${ }^{16}$ The $\mathrm{CCI}$ assigns 1 point for each condition to a patient with a history of myocardial infarction, congestive heart failure, peripheral vascular disease, cerebrovascular disease (a transient ischemic attack or cerebrovascular accident with few or no residual problems), dementia, chronic pulmonary disease, connective tissue disorders, peptic ulcers, mild liver disease, or diabetes in the absence of end-organ damage; 2 points for hemiplegia, moderate-to-severe renal disease, diabetes featuring end-organ damage, non-metastatic tumors, leukemia, lymphoma, and myeloma; 3 points for moderate or severe liver disease; and 6 points for metastatic solid tumors or acquired immunodeficiency syndrome. In addition, 1 point is added to the score for every decade over 40 years of age.

Patients were considered to exhibit peripheral neuropathy if the following criteria were met: patient exhibited typical clinical symptoms such as weakness, sensory symptoms and deficits, and reflex loss; symptoms matched diagnostic codes for several types of peripheral neuropathy; and electrodiagnostic tests confirmed that problems were localized to the peripheral nerves. We also assessed underlying diseases or medications that might contribute to peripheral neuropathy, including diabetes, renal insufficiency, nutritional deficiency, alcohol abuse, monoclonal gammopathy, and neurological disease. $^{21}$

\section{Statistical Methods}

Quantitative and qualitative data are represented by median values (with interquartile ranges [IQRs]) and percentages, respectively. The Mann-Whitney, chi-squared, or Fisher's exact test was used (as appropriate) to compare clinical data and HR-ARM parameters between SAR and control patients. We also compared the same parameters based on SAR status among patients exhibiting constipation and fecal incontinence. The associations between SAR status and balloon expulsion test (BET) and defecography test results were also assessed for constipated patients. Differences were considered statistically significant at $P<0.05$.

Table 1. Comparison of Demographic and Clinical Features Between Patients Exhibiting Spontaneous Anal Relaxation and Controls

\begin{tabular}{lccc}
\multicolumn{1}{c}{ Variables } & $\begin{array}{c}\text { Controls } \\
(\mathrm{n}=69)\end{array}$ & $\begin{array}{c}\text { SAR patients } \\
(\mathrm{n}=23)\end{array}$ & $P$-value \\
\hline Number of females & $47(68.1)$ & $15(65.2)$ & 0.802 \\
Median age $(\mathrm{yr})$ & $76(65.6-81.5)$ & $75(70.0-82.0)$ & 0.917 \\
Median BMI $\left(\mathrm{kg} / \mathrm{m}^{2}\right)$ & $22.2(20.7-24.6)$ & $21.6(19.5-24.7)$ & 0.427 \\
Main indication & & & 0.021 \\
$\quad$ Number of patients with constipation & $51(73.9)$ & $11(47.8)$ & \\
$\quad$ Number of patients with fecal incontinence & $18(26.1)$ & $12(52.2)$ & 0.028 \\
Median Charlson comorbidity index & $4(2.5-5)$ & $5(4-7)$ & 0.003 \\
Number of patients with peripheral neuropathy & $8(11.6)$ & $9(39.1)$ & 0.022 \\
Number of patients exhibiting diseases that potentially cause neuropathy & $32(46.4)$ & $17(73.9)$ & 0.014 \\
Number of diseases that potentially cause neuropathy & $0(0-1)$ & $1(0-2)$ & \\
\hline
\end{tabular}

${ }^{a}$ Each spontaneous anal relaxation (SAR) patient was matched with 3 control patients. Control patients were selected to match each SAR patient in terms of age, sex, and examination year.

BMI, body mass index.

Data are represented as number $(\%)$ or median (interquartile range). 


\section{Results}

\section{Clinical Features}

Sex distribution, age, and body mass index were similar between the 2 groups (Table 1). HR-ARM was more frequently indicated to assess fecal incontinence in SAR patients (52.2\%) than in controls $(26.1 \%, P=0.021)$. SAR patients (median score $=5$ ) had a higher median CCI score than controls (median score $=4, P$ $=0.003$ ). All patients exhibiting peripheral neuropathy evidenced polyneuropathy. Peripheral neuropathy was also significantly more common in SAR patients $(39.1 \%)$ than in controls $(11.6 \%, P=$ 0.022 ). There was a significant difference between the SAR patients $(72.7 \%)$ and the controls $(41.2 \%)$ regarding the presence of diseases that potentially cause peripheral neuropathy. Additionally, the SAR patients had a significantly higher incidence of diseases that potentially cause peripheral neuropathy. The following diseases were associated with peripheral neuropathy: diabetes $(n=25)$, hypothyroidism $(\mathrm{n}=19)$, alcohol abuse with/without vitamin deficiency ( $\mathrm{n}$ $=9)$, renal insufficiency $(\mathrm{n}=5)$, autoimmune conditions $(\mathrm{n}=3)$, chronic liver disease $(n=2)$, and lymphoma $(n=1)$.

\section{High-resolution Anorectal Manometry Parameters}

SAR patients exhibited lower rest and squeeze anal pressures (Table 2). The median maximal resting pressures of SAR and control patients were 14.9 (IQR, 12.4-19.8) $\mathrm{mmHg}$ and 45.4 (IQR, 32.8-60.5) $\mathrm{mmHg}$, respectively $(P<0.001)$. SAR patients exhibited a lower median maximal squeeze pressure than controls (110.1 [IQR, 57.9-138.1] mmHg vs 137.6 [IQR, 89.8-184.8] $\mathrm{mmHg}, P=0.047)$. During the bearing-down maneuver, SAR patients exhibited significantly lower residual anal and intrarectal pressures than controls ( $P=0.002$ and $P=0.025$, respectively). The median residual anal pressures for SAR patients and controls were 39.5 (IQR, 28.0-55.4) $\mathrm{mmHg}$ and 72.7 (IQR, 40.3-195.3) $\mathrm{mmHg}$, respectively, whereas the median intrarectal pressures for SAR patients and controls were 21.2 (IQR, 7.3-39.4) $\mathrm{mmHg}$ and 33.8 (IQR, 18.2-54.0) mmHg, respectively. However, the threshold volumes for the first sustained sensation, urge, and maximum discomfort did not differ between groups.

\section{Comparison of Spontaneous Internal Anal Sphincter Relaxation and Control Patients With Constipation}

We compared clinical data, HR-ARM parameters, and BET and defecography test results between SAR patients and controls with constipation (Table 3). Constipated patients with SAR had a

Table 2. Comparison of High-resolution Anorectal Manometry Parameters Between Patients Exhibiting Spontaneous Anal Relaxation and Controls

\begin{tabular}{|c|c|c|c|}
\hline Variables & $\begin{array}{l}\text { Controls } \\
(\mathrm{n}=69)\end{array}$ & $\begin{array}{l}\text { SAR patients } \\
\qquad(\mathrm{n}=23)\end{array}$ & $P$-value \\
\hline Resting stage & & & 0.021 \\
\hline Maximal pressure (mmHg) & $45.4(32.8-60.5)$ & $14.9(12.4-19.8)$ & $<0.001$ \\
\hline Mean pressure $(\mathrm{mmHg})$ & $38.8(27.6-54.7)$ & $12.2(10.5-15.8)$ & $<0.001$ \\
\hline Length of the HPZ $(\mathrm{cm})$ & $3.1(2.6-3.9)$ & $3.1(2.5-3.7)$ & 0.885 \\
\hline \multicolumn{4}{|l|}{ Squeezing stage } \\
\hline Maximal pressure (mmHg) & $137.6(89.8-184.8)$ & $110.1(57.9-138.1)$ & 0.047 \\
\hline Duration (sec) & $7.7(6.2-10.2)$ & $6.1(4-8.2)$ & 0.019 \\
\hline \multicolumn{4}{|l|}{ Bearing-down stage } \\
\hline Residual anal pressure (mmHg) & $72.7(40.3-105.3)$ & $39.5(28-55.4)$ & 0.002 \\
\hline Percentage anal relaxation $(\mathrm{mmHg})$ & $-77.0(-141.5--20)$ & $-155.0(-254--58)$ & 0.14 \\
\hline Intrarectal pressure $(\mathrm{mmHg})$ & $33.8(18.2-54.0)$ & $21.2(7.3-39.4)$ & 0.025 \\
\hline Rectoanal pressure gradient ( $\mathrm{mmHg}$ ) & $-30.3(-57.0-14.9)$ & $-22.5(-38--1.7)$ & 0.085 \\
\hline \multicolumn{4}{|l|}{ Duration of sensations } \\
\hline First sensation $(\mathrm{mL})$ & $30(20-40)$ & $30(20-40)$ & 0.369 \\
\hline Urge sensation $(\mathrm{mL})$ & $70(50-120)$ & $60(50-120)$ & 0.978 \\
\hline Maximal tolerable sensation (mL) & $120(80-160)$ & $120(60-180)$ & 0.853 \\
\hline
\end{tabular}

SAR, spontaneous anal relaxation; HPZ, high pressure zone.

Data are represented as median (interquartile range). 
Table 3. Comparison of Clinical Data and Physiologic Test Results Between Constipated Patients With and Without Spontaneous Anal Relaxation

\begin{tabular}{|c|c|c|c|}
\hline Variables & $\begin{array}{l}\text { Constipated patients } \\
\text { without SAR } \\
(\mathrm{n}=51)\end{array}$ & $\begin{array}{c}\text { Constipated patients } \\
\text { with SAR } \\
(\mathrm{n}=11)\end{array}$ & $P$-value \\
\hline \multicolumn{4}{|l|}{ Clinical data } \\
\hline Number of females & $32(62.7)$ & $7(63.6)$ & $>0.999$ \\
\hline Median age (yr) & $76(63.5-81.3)$ & $71(59.0-85.0)$ & 0.796 \\
\hline Median BMI $\left(\mathrm{kg} / \mathrm{m}^{2}\right)$ & $22.6(21.0-25.2)$ & $23.0(18.2-25.8)$ & 0.714 \\
\hline Charlson comorbidity index & $4(3-5)$ & $6(3-7)$ & 0.042 \\
\hline Incidence of peripheral neuropathy & $5(9.8)$ & $5(45.5)$ & 0.011 \\
\hline Number of patients exhibiting diseases that potentially cause neuropathy & $21(41.2)$ & $8(72.7)$ & 0.057 \\
\hline Incidence of diseases that potentially cause neuropathy & $0(0-1)$ & $1(0-2)$ & 0.026 \\
\hline \multicolumn{4}{|l|}{ HR-ARM data } \\
\hline Maximal resting pressure $(\mathrm{mmHg})$ & $52.4(36.4-68.1)$ & $13.3(12.0-18.6)$ & $<0.001$ \\
\hline Mean resting pressure (mmHg) & $47.3(32.4-61.7)$ & $12.0(10.4-15.2)$ & $<0.001$ \\
\hline Length of the HPZ (cm) & $3.1(2.5-3.9)$ & $3.0(0.80-3.9)$ & 0.692 \\
\hline Maximal squeezing pressure ( $\mathrm{mmHg}$ ) & $151.5(108.7-204.5)$ & $114.7(54.7-160.1)$ & 0.061 \\
\hline Squeeze duration (sec) & $7.5(5.4-9.6)$ & $4.9(4.0-8.0)$ & 0.078 \\
\hline Residual anal pressure (mmHg) & $82(55.1-110.8)$ & $34.4(25.9-41.3)$ & 0.001 \\
\hline Percentage anal relaxation (\%) & $-69(-158--18)$ & $-107(-349--46)$ & 0.131 \\
\hline Intrarectal pressure (mmHg) & $42.6(21.5-58.6)$ & $16.9(7.3-57.9)$ & 0.092 \\
\hline Rectoanal pressure gradient ( $\mathrm{mmHg}$ ) & $-37.5(-62.1--15.2)$ & $-19.6(-38.0-22.5)$ & 0.033 \\
\hline First sensation $(\mathrm{mL})$ & $30(20-40)$ & $30(20-40)$ & 0.287 \\
\hline Urge sensation (mL) & $70(50-120)$ & $60(50-120)$ & 0.683 \\
\hline Maximal tolerable sensation $(\mathrm{mL})$ & $120(80-180)$ & $130(60-180)$ & 0.963 \\
\hline \multicolumn{4}{|l|}{ Balloon expulsion test ${ }^{a}$} \\
\hline Number of patients that failed to expel balloon & $21(42.0)$ & $3(27.3)$ & 0.502 \\
\hline Median expulsion time (sec) & $40(10-180)$ & $20(8-180)$ & 0.275 \\
\hline \multicolumn{4}{|l|}{ Defecography ${ }^{\mathrm{b}}$} \\
\hline Incidence of impaired rectal emptying at $30 \mathrm{sec}$ & $38(84.4)$ & $4(44.4)$ & 0.019 \\
\hline Incidence of impaired rectal emptying at $60 \mathrm{sec}$ & $37(87.2)$ & $2(22.2)$ & 0.001 \\
\hline Incidence of large rectocele & $7(15.6)$ & $1(11.1)$ & $>0.999$ \\
\hline Incidence of rectal intussusception & $4(8.9)$ & $1(11.1)$ & $>0.999$ \\
\hline Incidence of patulous anus & $14(31.1)$ & $3(33.3)$ & $>0.999$ \\
\hline Location of ARJ at rest & $-0.8(-1.7-0.9)$ & $1.8(0.4-2.4)$ & 0.005 \\
\hline Location of ARJ during evacuation & $2(0.4-3.1)$ & $3.4(1.6-6.4)$ & 0.029 \\
\hline
\end{tabular}

${ }^{\mathrm{a} O n e}$ constipated patient did not undergo the balloon expulsion test.

${ }^{\mathrm{b}}$ Eight constipated patients did not undergo barium defecography.

SAR, spontaneous internal anal sphincter relaxation; BMI, body mass index; HR-ARM, high-resolution anorectal manometry; HPZ, high pressure zone; ARJ, anorectal junction.

Data are represented as number (\%) or median (interquartile range).

higher CCI score (6 vs $4, P=0.042$ ), higher incidence of peripheral neuropathy ( $45.5 \%$ vs $9.8 \%, P=0.011$ ), and higher incidence of diseases that potentially cause peripheral neuropathy ( 1 vs $0, P$ $=0.026)$ than control patients. Maximal resting pressures (13.3 $\mathrm{mmHg}$ vs $52.4 \mathrm{mmHg}$ ), mean resting pressures $(12 \mathrm{mmHg}$ vs $47.3 \mathrm{mmHg}$ ), residual anal pressures while bearing-down (34.4 $\mathrm{mmHg}$ vs $82 \mathrm{mmHg})$, and rectoanal pressure gradients $(-19.6$
$\mathrm{mmHg}$ vs $-37.5 \mathrm{mmHg}$ ) were also different between SAR patients and controls with contipation (all $P<0.05$ ). However, BET test results were similar between the 2 groups. Rectal evacuation disorder was defined as failure to evacuate $>66 \%$ of rectal contrast within 60 seconds in the barium defecography test. The proportion of rectal evacuation disorder patients was higher among those with than without SAR (87.2\% vs $22.2 \%, P=0.001)$. SAR patients 
exhibited a lower median ARJ location value at rest $(1.8 \mathrm{~cm}$ vs -0.8 $\mathrm{cm}, P=0.005)$ and during evacuation $(3.4 \mathrm{~cm}$ vs $2.0 \mathrm{~cm}, P=$ 0.029 ) compared to controls.

\section{Comparison of Spontaneous Internal Anal Sphincter Relaxation and Control Patients With Fecal Incontinence}

Only resting anal pressures differed between incontinent SAR patients and controls. Incontinent SAR patients exhibited lower maximal (16.6 mmHg vs $35.5 \mathrm{mmHg}, P<0.001)$ and mean (13.3 $\mathrm{mmHg}$ vs $30 \mathrm{mmHg}, P<0.001)$ resting pressures.

\section{Discussion}

Our controlled observational study is the first to indicate that application of HR-ARM can elucidate the association among SAR status, peripheral neuropathy and severe comorbidities in patients with defecatory disorders. These associations were more marked in constipated patients.

The presence of the SAR in patients with neurogenic or diabetic fecal incontinence is well documented. ${ }^{8-11}$ To our knowledge, conventional ARM was used to derive these conclusions, which were confirmed in this study using HR-ARM. Consistent with previous studies, we found that SAR was associated with a lower resting anal pressure, which reflects IAS dysfunction. ${ }^{8-11}$ When the association between SAR and resting anal pressure was further assessed in patients with fecal incontinence, this association was maintained. In this sense, SAR assessment is useful for evaluating IAS dysmotility.

We identified constipated patients without fecal incontinence who exhibited SAR. Notably, these patients exhibited a lower ARJ both at rest and during evacuation than did constipated patients without SAR. Our results imply that SAR is associated with excessive perineal descent, which in turn injures the pudendal nerves and triggers progressive denervation of the external anal sphincters supplied by these nerves. It is unclear why SAR (ie, IAS dysfunction) is associated with excessive perineal descent in constipated patients. A reduced resting anal pressure is found in about two-thirds of patients with neurogenic fecal incontinence; theoretically, patients with neuropathic damage to the external anal sphincter but normal IAS function. ${ }^{22}$ It has been hypothesized that IAS dysfunction might be associated with loss of support from the surrounding external anal sphincter. ${ }^{23}$ It is also possible that IAS dysfunction results from autonomic denervation given that the IAS is innervated by both the autonomic and enteric nervous systems. ${ }^{2,3,5}$

We found an association between SAR and peripheral neu- ropathy. The prevalence of peripheral neuropathy in patients with SAR was approximately $40 \%$, which was more than 3 times the prevalence in patients without SAR. Furthermore, compared to controls, SAR patients exhibited more combined diseases/history of medications that potentially trigger neuropathy. SAR patients also exhibited higher CCI scores (ie, severe comorbidity levels) than control patients. The CCI is a valid measure of disease burden and mortality risk. ${ }^{16}$ Thus, assessing SAR status may help to predict the morbidity and mortality of patients with anorectal disorders.

Our study is limited by the retrospective work, the relatively small sample size, and the lack of healthy controls. Any retrospective case-control study is innately prone to selection bias. Longer HR-ARM recordings in the anal canal may also detect SAR better. In addition, we did not compare endoanal ultrasound and HRARM data, and thus lack information on the relationship between SAR status and structural IAS abnormalities. Further research in these areas are needed.

In conclusion, this controlled observational study using HRARM is the first to evaluate SAR status in both constipated and fecally incontinent patients. SAR incidence is higher in fecally incontinent patients. We also found that SAR was associated with peripheral neuropathy and high CCI scores. This information can be used to assess morbidity and mortality risks in patients with anorectal disorders.

Financial support: This work was supported by the Soonchunhyang University Research Fund.

\section{Conflicts of interest: None.}

Author contributions: Concept and design: Tae Hee Lee; supervision and critical reviews: Joon Seong Lee; data collection and/or processing: Tae Hee Lee, Joon Seong Lee, Jeeyeon Kim, Jin-Oh Kim, Su Jin Hong, Young Sin Cho, Seong Ran Jeon, and Hyun Gun Kim; writing: Tae Hee Lee and Joon Seong Lee; and statistical analysis: Suyeon Park.

\section{References}

1. Lee TH, Bharucha AE. How to perform and interpret a high-resolution anorectal manometry test. J Neurogastroenterol Motil 2016;22:46-59.

2. Rattan $\mathrm{S}$. The internal anal sphincter: regulation of smooth muscle tone and relaxation. Neurogastroenterol Motil 2005;17(suppl 1):50-59.

3. Kumar L, Emmanuel A. Internal anal sphincter: clinical perspective. Surgeon 2017;15:211-226.

4. Cobine CA, Hannah EE, Zhu MH, et al. ANO1 in intramuscular interstitial cells of Cajal plays a key role in the generation of slow waves and 
tone in the internal anal sphincter. J Physiol 2017;595:2021-2041.

5. Keef KD, Cobine CA. Control of motility in the internal anal sphincter. J Neurogastroenterol Motil 2019;25:189-204.

6. American Gastroenterology Association, Bharucha AE, Dorn SD, Lembo A, Pressman A. American Gastroenterological Association medical position statement on constipation. Gastroenterology 2013;144:211-217.

7. Bharucha AE. Fecal incontinence. Gastroenterology 2003;124:16721685.

8. Sun WM, Read NW, Miner PB, Kerrigan DD, Donnelly TC. The role of transient internal sphincter relaxation in faecal incontinence? Int J Colorectal Dis 1990;5:31-36.

9. Farouk R, Duthie GS, Pryde A, McGregor AB, Bartolo DC. Internal anal sphincter dysfunction in neurogenic faecal incontinence. Br J Surg 1993;83:259-261.

10. Farouk R, Duthie GS, MacGregor AB, Bartolo DC. Evidence of electromechanical dissociation of the internal anal sphincter in idiopathic fecal incontinence. Dis Colon Rectum 1994;37:595-601.

11. Sun WM, Katsinelos P, Horowitz M, Read NW. Disturbances in anorectal function in patients with diabetes mellitus and faecal incontinence. Eur J Gastroenterol Hepatol 1996;8:1007-1012.

12. Prichard D, Harvey DM, Fletcher JG, Zinsmeister AR, Bharucha AE. Relationship among anal sphincter injury, patulous anal canal, and anal pressures in patients with anorectal disorders. Clin Gastroenterol Hepatol 2015;13:1793-1800, e1.

13. Tesfaye $\mathrm{S}$. Recent advances in the management of diabetic distal symmetrical polyneuropathy. J Diabetes Investig 2011;2:33-42.

14. AlAmeel T, Andrew MK, MacKnight C. The association of fecal in- continence with institutionalization and mortality in older adults. Am J Gastroenterol 2010;105:1830-1834.

15. Koloski NA, Jones M, Wai R, Gill RS, Byles J, Talley NJ. Impact of persistent constipation on health-related quality of life and mortality in older community-dwelling women. Am J Gastroenterol 2013;108:11521158.

16. Charlson ME, Pompei P, Ales KL, Mackenzie CR. A new method of classifying prognostic comorbidity in longitudinal studies: development and validation. J Chronic Dis 1987;40:373-383.

17. Halligan S, Malouf A, Bartram CI, Marshall M, Hollings N, Kamm MA. Predictive value of impaired evacuation at proctography in diagnosing anismus. AJR Am J Roentgenol 2001;177:633-636.

18. Minguez M, Herreros B, Sanchiz V, et al. Predictive value of the balloon expulsion test for excluding the diagnosis of pelvic floor dyssynergia in constipation. Gastroenterology 2004;126:57-62.

19. Collinson R, Cunningham C, D'Costa H, Kindsey I. Rectal intussusception and unexplained faecal incontinence: findings of a proctographic study. Colorectal Dis 2009;11:77-83.

20. Jorge JM, Wexner SD. Etiology and management of fecal incontinence. Dis Colon Rectum 1993;36:77-97.

21. England JD, Asbury AK. Peripheral neuropathy. Lancet 2004;363:21512161.

22. Neill ME, Parks AG, Swash M. Physiological studies of the anal sphincter musculature in faecal incontinence and rectal prolapse. Br J Surg 1981;68:531-536.

23. Lubowski DZ, Nicholls RJ, Burleigh DE, Swash M. Internal anal sphincter in neurogenic fecal incontinence. Gastroenterology 1988;95:997-1002. 